\title{
Crítica, poética e relações de gênero: uma releitura de Memórias de um sargento de milícias
}

\author{
Edwirgens Aparecida Ribeiro Lopes de Almeida
}

Resumo:

Reinterpretando as contradições existentes nas críticas oitocentista e moderna sobre Memórias de um sargento de milícias, de Manuel Antônio de Almeida, este ensaio propõe uma releitura do processo de construção da poética do romance, bem como da verossimilhança com que foram construídas as relações de gênero presentes na mesma.

Palavras-chave: crítica, poética, masculino, feminino, verossimilhança.

[As] Memórias serão tratadas como um romance realista a sério, em que está em jogo o sentido da vida contemporânea. Noutras palavras, trata-se da passagem da crítica de edificação nacional à crítica estética; da crítica de função puramente local à crítica de sondagem do mundo contemporâneo; da crítica em que o nacional é comemorado à crítica em que ele é historicizado.

Roberto Schwarz

A publicação da obra Memórias de um sargento de milícias, inicialmente em folhetins, se deu em substituição à folha em francês que antes integrava o jornal carioca Correio Mercantil. Apresentando uma poética que destoa do tom e da ideologia romântica, a narrativa de Manuel Antônio de Almeida teve poucos leitores no século $\mathrm{XX}$.

Contudo, estudos recentes sobre os contemporâneos de Manuel Antônio demonstram que tanto o autor quanto a sua criação causaram inquietações no meio artístico do século XIX. Também desmentem o desinteresse atribuído à obra no século XIX. Esses textos, segundo Bernardo de Mendonça (1992), são de conhecimento recente; talvez, por isso, a crítica, desinformada da existência desses escritos, tanto disseminou a concepção de desinteresse pelo autor. Em artigo publicado em 1876, Joaquim Manuel de Macedo destaca o gosto do romancista pelas letras e declara que, mesmo sendo médico, nunca se lembraram de chamá-lo para visitar doentes, pois, naturalmente, já havia se nomeado literato, quando escreveu um "estudo ameno e precioso de antigos costumes do país, e de coisas nele passadas, que mereceu 
aplausos gerais, e brilhou como aurora promissora de fulgurante dia" (MACEDO, 1991, p. 145).

Franklin Távora, na década de 1870, fazendo uma revisão dos talentos de 1800, aponta que Manuel Antônio de Almeida a todos se avantajou, pois deixou "um só quadro, um só painel, quadro brilhante, painel imenso, em que há vida, graça e colorido nativo" (TÁVORA, 1991, p. 156). Seguindo a mesma trilha, no ano de 1880, Sílvio Romero (1991) admite que a obra Memórias de um sargento de milícias é uma das mais enaltecidas das letras brasileiras e afirma que o livro sobreviveu graças ao talento do ficcionista em não se enveredar pelos meios mais comuns de fazer uma literatura nacional, mas inovar o nacional descrevendo os usos e costumes do povo do Rio de Janeiro do começo do século XIX.

Como observou José Veríssimo, analisando a obra nos anos de 1894, 1900 e 1916, é embaraçoso classificar a obra Memórias de um sargento de milícias em uma escola literária. Inicialmente a acusa de ser mal escrita, porém admite a beleza do conteúdo das Memórias. Diante disso, declara: "eu considero-o um dos mais característicos da nossa literatura, um dos mais nacionais que tenhamos, um dos que menos intencional e mais naturalmente nos dão aquela impressão de nacionalismo a que no começo aludi" (VERÍSSIMO, 1978, p. 296). Em seu último exame sobre a narrativa almeidiana, José Veríssimo (1978, p. 292) aponta bem menos restrições ao romance que em suas primeiras leituras sobre a obra. Por outro lado, constata que a atração pela leitura da narrativa deve-se à riqueza de seu conteúdo. Segundo ele, as pessoas

que procuram no romance não a distração de uma ingênua narrativa com que o homem, eterna criança, se diverte ou consola, mas a história psicológica da sociedade, a representação da vida nos traços mais verdadeiros, mais vivos e ao mesmo tempo mais conformes ao tipo que da perfeição plástica se fazem, lerão este livro com simpatia.

Entende-se assim que os fatores destacados por Veríssimo como negativos no romance, como a linguagem coloquial, tenham sido valorizados e enaltecidos pela crítica do século XX. Possivelmente, por se tratar de contextos e de influências estéticas distintas, a crítica realizada por José Veríssimo, no século XIX, adequa-se aos pressupostos românticos.

Discordamos da posição de Veríssimo quando explica a origem e a trajetória do herói Leonardo: "Desavindos os pais, por motivo de mútua infidelidade de ambos que em amor não gostavam, como Camões: 'de arder em uma só chama'" (VERÍSSIMO, 1978, p. 297). A afirmação de Veríssimo leva-nos a compreender que tanto LeonardoPataca quanto Maria-da-Hortaliça cometem traições à procura de novas relações amorosas. Entretanto, a nossa discussão baseia-se na evidência de que, na obra, apenas as mulheres que se envolvem afetivamente com Leonardo-Pataca cometem a transgressão. Assim, Leonardo-Pataca se entrega definitivamente às relações e persiste na permanência delas, mesmo sendo traído, e por esse motivo passa por inúmeros outros infortúnios.

Constatada a riqueza de interpretações presentes nas leituras do século XIX, deixamos de lado inúmeros outros estudos sobre a narrativa das Memórias e passamos a verificar alguns críticos do século XX. Interessa-nos o exame de Mário de Andrade, que publica, em 1928, a obra Macunaíma, cuja personagem central se constitui na 
mistura do índio romântico de José de Alencar e do sensualismo e ociosidade do herói de Manuel Antônio de Almeida, intensificada pela falta de caráter. No estudo que prefacia a obra de Manuel Antônio de Almeida da edição Martins de 1941, Mário de Andrade (1978, p. 303) refere-se a Memórias de um sargento de milícias como "um dos romances mais interessantes, uma das produções mais originais e extraordinárias da ficção americana".

Em outra observação, relevante para a presente pesquisa, o autor e crítico modernista refere-se a Leonardo como o "sargento graduado pelo amor sacrificial de várias mulheres" (ANDRADE, 1978, p. 306). É com vistas a analisar essa postura antiromântica que vai nossa discussão. Leonardo é protegido pela maioria das mulheres da narrativa. Não pratica nenhuma ação para se dar bem. Consegue um posto de sargento, a herança do padrinho, o casamento nos moldes burgueses, além de se safar de várias confusões sem que tenha feito nenhum esforço. Ainda nessa direção, acrescenta que o mesmo não falará umas dez frases em toda a narrativa recheada de diálogos. Ele não precisa falar, falam por ele.

Por sua lógica, entendemos que, através da leitura do crítico, o narrador destaca uma postura antitradicional de Leonardo, já que é submisso e passivo às mulheres, e omisso quanto às situações. Em controvérsia, revela uma posição bastante tradicional, uma vez que deixa claro que, para ser "macho", não é suficiente pertencer ao sexo masculino e mostrar para a sociedade um corpo forte e robusto, mas é preciso trabalhar, solucionar seus próprios problemas, conquistar as mulheres; enfim, agir com autonomia e determinação. Vê-se, no excerto abaixo, o comentário de Mário de Andrade (1978, p. 312) sobre a construção da identidade de Leonardo pelas pessoas com as quais convive:

Não é um homem que se faz por si, os outros é que o fazem por ele, rabode-saia com que todas as mulheres de todas as idades se engraçam, Ihe fornecem espontaneamente pão, guarida, amor, sacrifício e aquelas eternas especulações de empenhos e cartuchos com que o macho apenas de corpo se livra de castigos e trabalhos e atinge os seus galões de sargento no fim.

Repensando esse rompimento com a tradição romântica, Massaud Moisés constata a descrição anti-romântica que o narrador faz de Luisinha. São palavras do narrador que delineiam um retrato natural da personagem. Vejamos o seguinte trecho extraído das Memórias, que pode endossar a concepção do crítico:

Desde o dia em que Leonardo fizera a sua declaração amorosa, uma mudança notável se começou a operar em Luisinha, cada hora se tornava mais sensível à diferença tanto de físico como do seu moral. Seus contornos começavam a redondar-se; seus braços, até ali finos e sempre caídos, engrossavam-se e tornavam-se mais ágeis; suas faces magras e pálidas, enchiam-se e tomavam essa cor que só sabe ter o rosto da mulher em certa época da vida; a cabeça, que trazia habitualmente baixa, erguiase agora graciosamente; os olhos, até ali amortecidos, começavam a despedir lampejos brilhantes; falava, movia-se, agitava-se. (ALMEIDA, 1999, p. 68)

Além do realismo destacado por Moisés (1985), no fragmento citado, podemos observar que 0 narrador nos revela o homem, representado pela personagem Leonardo, facilmente transformado ou sensibilizado pelos sentimentos. Acreditamos 
que essa postura masculina modifica ou reorganiza as relações de gênero próprias da sociedade patriarcal em que se passa a história.

Essa transformação nas relações sociais se dá, ainda, no comportamento apresentado pela personagem Vidinha. Como tipificação de muitas mulheres modernas, Vidinha é aquela que não camufla; ao contrário, desmascara, é ativa, enfrenta brigas, busca seus objetivos e, de acordo com o narrador, é "uma formidável namoradeira". Faz parte do rol das mulheres atípicas para uma sociedade tradicional. Vidinha é o oposto da personagem Luisinha, já que esta encarna a prescrição patriarcal de aceitação e subserviência. Com base nesses perfis femininos na obra, Ivete Walty (1980, p. 56) identifica "duas faces das mulheres daquele tempo: a de vida livre e a de comportamento recatado".

Em um dos estudos mais alentados acerca das Memórias, Antonio Candido, perpassando as classificações de romance picaresco, malandro, documentário e representativo, explica que Leonardo é "o primeiro grande malandro que entra na novelística brasileira". Sob essa perspectiva, Walnice Nogueira Galvão (1976, p. 32) comunga com Candido da observação de que Manuel Antônio de Almeida é o primeiro a fixar, em literatura, o caráter nacional brasileiro já que a ficção, particularmente do século $\mathrm{XX}$, tem atribuído ao brasileiro as características de "vagabundagem, preguiça, sensualidade, indisciplina, vivacidade de espírito, nossa modalidade de 'inteligência' e, sobretudo simpatia".

Candido destaca ainda que, nessa sociedade narrada no romance almeidiano, as relações sociais são constituídas pelos estratos da ordem e da desordem, e "as Memórias são um livro agudo como percepção das relações humanas tomadas em conjunto. Se não teve consciência nítida, é fora de dúvida que o autor teve maestria suficiente para organizar um certo número de personagens segundo intuições adequadas da realidade social" (CANDIDO, 1993, p. 37).

Como resultados do trabalho com os códigos lingüísticos, literários e ideológicos, personagens, espaço e tempo enredam o tecido narrativo dando "ares" de realidade ao narrado. Como postula Candido, essa aproximação com o real, sendo fruto da intuição do romancista, permite-nos examinar as relações sociais, incluindo-se as de gênero, da época.

Sendo "feitas de papel", as personagens que circulam pelas ruas da cidade são inscritas numa sociedade que também é fruto de uma representação. Se a exibição dessa sociedade se dá pela dialética da ordem e da desordem, as relações de gênero também oscilam entre esses dois opostos. A diversidade das condutas das personagens do romance em questão é percebida por meio dessa dialética.

Centrada em uma sociedade administrada por homens e em que os discursos são especialmente masculinos, os homens se tornaram coadjuvantes dessa história que tem as ações femininas como fio condutor. Nas relações estabelecidas na narrativa, os triângulos amorosos geralmente configuram-se sob a forma masculino-femininomasculino, estrutura menos comum nessas sociedades. Podemos exemplificar com as relações existentes entre o Capitão do navio, Maria-da-Hortaliça e Leonardo-Pataca, entre Leonardo-Pataca, Cigana e Mestre-de-cerimônias, e entre Leonardo, Luisinha, e José Manuel.

Sob essa desestabilização das relações de gênero, Maria Ângela D'Incao (1997) discute que as mulheres do povo eram as mais livres para amar pessoas de sua 
condição social, já que nessas relações não havia interesses econômicos. Com base na inscrição da autonomia e da liberdade dessa classe, Manuel Antônio de Almeida deixou de lado a representação da classe predominante para revelar os diversos modos de comportamentos que uma mesma sociedade pode agregar.

Assim, neste cenário carioca dos anos de 1800, mesmo sendo uma construção masculina, as mulheres como Maria-da-Hortaliça e a Cigana, são representações da desestabilização das relações de gênero, pois abandonam o ambiente familiar para realizarem seus desejos, uma vez que, naquela época, à esposa caberia apenas o papel de recato, submissão e acolhimento da família. É bom ressaltar que a busca de satisfação pessoal descrita na narrativa ainda tem a mediação da intencionalidade masculina, pois são registros feitos pelo masculino. Então, essas mulheres não são de todo livres. Como ressalta Ruth Silviano Brandão (1993, p. 230), "[p]resa de um sistema de representações viris, a mulher se lê anunciada num discurso que se faz passar pelo discurso de seu desejo".

Da mesma forma, é comum encontrarmos a voz feminina endossando as características de recato e de subordinação da mulher no imaginário mundo das Memórias. Como se pode depreender da afirmação da beata, na obra em análise, a respeito da atitude agressiva de Leonardo-Pataca com Maria-da-Hortaliça após a traição desta:

- É o que Ihe digo: a saloiazinha era da pele do tinhoso!

- E parecia uma santinha... e o Leonardo o que lhe fez?

- Ora, desancou-a de murros, e foi o que fez com que ela abalasse mais depressa com o capitão... pois olhe, não teve razão; o Leonardo é um rapagão; ganhava boas patacas e tratava dela como de uma senhora!... (ALMEIDA, 1999, p. 25)

Nota-se que, embora sejam biologicamente mulheres, reproduzem o discurso, a ideologia do masculino, do patriarcalismo. Como manifestação desse discurso e dessa ideologia masculina, a personagem ratifica o tratamento de violência de LeonardoPataca sobre Maria-da-Hortaliça e ameniza a ilegalidade da agressão pelo amparo dado por Leonardo à companheira. Na expressão "tratava dela como de uma senhora", a beata reafirma a depreciação da conduta feminina atrelada a seu grupo de origem, o de imigrante portuguesa e de camponesa. A discussão nos remete a pensar que o tratamento dado a Maria por Leonardo era melhor que aquele que ela merecia.

No caso da personagem Luisinha, pode-se afirmar que ela se enquadra dentro dos padrões de normalidade de feminino no contexto tradicional. Ela sequer denota alguma intenção, pretensão ou desejo. É um verdadeiro fantoche nas mãos de Dona Maria, de José Manuel e do próprio narrador. Sobre essa conduta impotente, pusilânime e inoperante da mulher em relação ao masculino, comentam Branca Moreira Alves e Jacqueline Pitanguy (1983, p. 39): "A mulher, ainda uma escrava, permanece em silêncio [...] Subjugada pelo domínio masculino, ela nem sequer aspira à sua própria libertação, o homem é que deve libertá-la".

Quanto às mulheres de Memórias de um sargento de milícias, percebe-se que há aquelas desejantes e autoconfiantes, assim como também encontramos aquelas que reproduzem os ditames tradicionais. Vidinha, Dona Maria, Maria-da-Hortaliça, dentre outras, podem ser pensadas como as verdadeiras protagonistas da história. Sejam ações legítimas ou ilegítimas, são elas quem as promovem. Em relação à Luisinha, o 
mesmo não pode ser pensado, pois esta se sujeita ao poder e ao controle do masculino. É fácil notar que, devido à diversidade de funções que essas mesmas mulheres exercem na sociedade, elas são fundamentais para o desenrolar do novelo narrativo.

Como exemplo desse sinal de poder feminino no enredo romanesco, recorremos a Dona Maria, uma velha rica que tinha o costume das demandas judiciais. Não havia homem que pudesse enganá-la; conhecia todos os termos jurídicos e deles fazia uso sempre que necessário. Em seu discurso emerge uma voz feminina reafirmando as convenções da sociedade tradicional e em sua conduta é revelado um perfil antitradicional. Apresentava argumentos convincentes, havia clareza e determinação em suas decisões, enfrentava o poder masculino e, inclusive, aqueles representantes da justiça, sem que as faculdades afetivas predominassem sobre as intelectuais.

Consideramos essa personagem distinta do estereótipo dado às mulheres nos costumes patriarcais, porque o narrador a destaca como conhecedora das questões da lei de seu tempo. Suas ações não se limitavam à esfera doméstica e, merecendo o respeito, a aceitação e a estima dos homens ao se envolver no meio público. Era uma mulher de classe social superior àquelas mencionadas no texto; sua presença era sempre marcada por forte dose de razão. Assiste-se, assim, ao tratamento diferenciado dado a Dona Maria pelas outras personagens da narrativa sejam elas masculinas ou femininas. Tal postura revela-nos que, além do pertencimento ao gênero masculino, o status socioeconômico é um relevante elemento utilizado no desequilíbrio das diferenças entre os gêneros na sociedade encenada em Memórias.

Conforme destacamos, nas culturas tradicionais, a participação das mulheres do povo, no ambiente público, é motivo de descrédito da sua imagem. Contraditoriamente, o mesmo não ocorre com as mulheres de "elite". Esclareçamos, ainda, que as transgressões e ações das mulheres populares, aqui comentadas, são ridicularizadas pela população, enquanto aquelas demandas e ações propostas por Dona Maria são respeitadas e aplaudidas pelos homens e mesmo pelas outras mulheres. Com base nessa interpretação, estamos evidenciando que, durante o patriarcalismo, a supremacia de um gênero sobre o outro se dá, também, por meio da condição econômica.

Diante desta exposição, é valido ratificar que tanto o discurso histórico quanto o discurso literário têm comumente questionado a existência de modelos rígidos de sociedades. Essa diversidade de comportamentos sociais na narrativa em questão é determinada pela influência cultural e histórica, assim como pelo aspecto situacional e pelo caráter biológico, não exibindo, em todas as circunstâncias, os protótipos de gêneros, como indiciam as tradições patriarcais.

Abstract:

Reinterpreting the existent contradictions in nineteenth-century and modern criticisms on Memórias de um sargento de milícias (Sergeant of Militias Memories), by Manuel Antônio de Almeida, this essay proposes a new reading of the romance's poetics 
construction, as well as of the verisimilitude with which the gender relationships were built in the work.

Keywords: criticism, poetic, masculine, feminine, verisimilitude.

\section{Referências}

ALMEIDA, Manuel Antônio de. Memórias de um sargento de milícias. Rio de Janeiro: Ediouro, 1999.

ALVES, Branca Moreira; PITANGUY, Jacqueline. O que é feminismo. São Paulo: Brasiliense, 1983.

ANDRADE, Mário de. Introdução. LARA, Cecília de (Org.) Memórias de um sargento de milícias - Edição crítica. Rio de Janeiro: LTC, 1978. p. 303-315.

BRANDÃO, Ruth Silviano. Mulher ao pé da letra. Belo Horizonte: UFMG, 1993.

CANDIDO, Antonio. O discurso e a cidade. São Paulo: Duas Cidades, 1993.

D'INCAO, Maria Ângela. Mulher e família burguesa. In: DEL PRIORI, Mary (Org.).

História das mulheres no Brasil. São Paulo: Contexto, 1997. p. 223-240.

GALVÃO, Walnice Nogueira. Saco de gatos. São Paulo: Duas Cidades, 1976.

MACEDO, Joaquim Manuel de. O elogio dos protetores. In: MENDONÇA, Bernardo de. Obra dispersa - Manuel Antônio de Almeida. Rio de Janeiro: Graphia, 1991. p. $145-146$.

MENDONÇA, Bernardo de. Obra dispersa - Manuel Antônio de Almeida. Rio de Janeiro: Graphia, 1991.

MOISÉS, Massaud. História da literatura brasileira. São Paulo: Cultrix, 1985.

ROMERO, Sílvio. Gabos em demasia. In: MENDONÇA, Bernardo de. Obra dispersa - Manuel Antônio de Almeida. Rio de Janeiro: Graphia, 1991. p. 158.

SCHWARZ, Roberto. Que horas são? Ensaios. São Paulo: Companhia das Letras, 2002.

VERÍSSIMO, José. História da literatura brasileira. 3. ed. Rio de Janeiro: J. Olympio, 1954.

TÁVORA, Franklin. Almeidinha e o exmo. sr. Conselheiro. In: MENDONÇA, Bernardo de. Obra dispersa - Manuel Antônio de Almeida. Rio de Janeiro: Graphia, 1991. p. 155-157.

WALTY, Ivete. Implicações sociais do elemento picaresco nas Memórias de um sargento de milícias. Belo Horizonte: FALE, 1980. (Dissertação de mestrado). 